\title{
LA TABLA DE CEBES EN LA BIBLIOTECA NACIONAL
}

\author{
Eduardo Báez Macías
}

La Tabla de Cebes, obra moralizante compuesta según el modelo de los diálogos platónicos, fue sin duda una de las lecturas preferidas en los si. glos del renacimiento y del barroco, por una sociedad avezada en el lenguaje artificioso de los símbolos y los emblemas, que al mismo tiempo se esforzaba por recuperar a los clásicos incorporándolos a sus programas de didáctica moral. Lo sorprendente está en que el manejo de tales símbolos fuera accesible, lo mismo al personaje culto y refinado, que al hombre común que cuando menos recibía, por sencilla que fuese, una seria advertencia sobre las consecuencias de una determinada conducta.

En la Biblioteca Nacional, en la sección que conocemos como Fondo de Origen, hemos tenido la suerte de encontrar un ejemplar de la edición de 1701 de dicha obra, ${ }^{1}$ verdadera joya bibliográfica realizada por los impresores flamencos Henrico y Cornelio Verdussen, quienes la editaron encuadernada en un solo volumen con otras dos del mismo género: el Enchiridion de Epicteto y el Teatro Moral de la vida humana, libro compuesto a base de emblemas.

La divulgación de la Tabla se remonta al siglo XV, en que se citan hasta quince versiones latinas. En lengua castellana se hizo una primera edición en París, en el año de 1532, que pronto fue tildada de oscura y confusa. En 1549 apareció otra versión en Amberes, traducida por Juan Jarava, y una tercera en Córdoba en 1585, con traducción directa del griego por Ambrosio de Morales, humanista al servicio de Felipe II. Dos ediciones más aparecieron en el XVI, casi seguidas, y una cuando menos en el XVII. ${ }^{2}$ La de los Verdussen sería propiamente una reedición de la tercera, pues se utilizaron la traducción y los comentarios de Morales, aunque en esta ocasión los editores tuvieron la excelente idea de agregar al texto una "estampa figurativa" para la mejor comprensión de la letra, "sin reparar en el gran gasto" que tal cosa implicaba. El agregado resultó ser un magnífico grabado en metal de 25 por $35 \mathrm{~cm}$, plegable, pero sin alguna indicación que identifique al autor. Los grabados que ilustran el libro consor-

1 Este artículo constituye un subproducto de la investigación principal que me encuentro realizando en la Biblioteca Nacional en colaboración con Jorge Guerra Ruíz y Judith Puente León, sobre grabados en libros de los siglos XVI a XVIII.

${ }^{2}$ Vid Palau, Antonio. Manual del librero Hispanoamericano. 2a. Ed, Gerona, JM. Viader impresor, 1950. Tomo III, p. 354 
te, el Teatro Moral, son del celebérrimo Otto Venio, pero el de la Tabla se debe evidentemente a otra mano de menor maestría. ${ }^{3}$

El filósofo Cebes surge vinculado a la muerte de Sócrates, en los diálogos de Critón y Fedón. El maestro ateniense estaba acusado de corromper a la juventud, con su obstinada curiosidad de saber lo que pasaba en los cielos y en la tierra y por enseñar, apoyándose en Anaxágoras de Clazomenes, que el sol era una piedra y la luna una tierra. Era un impío, decían sus acusadores, que negaba la existencia de los dioses. Por una mayoría insignificante los jueces le declararon culpable y le condenaron a muerte, que de acuerdo con la costumbre tendría que procurarse él mismo bebiendo una dosis de veneno. Pero la sentencia no pudo ejectutarse de inmediato, como sus enemigos pretendían, porque ya el sacerdote de Apolo había colocado la corona en la proa del buque que los atenienses enviaban cada año a Delos, como agradecimiento al dios que había permitido, en los tiempo heroicos, que Teseo y las siete jóvenes parejas que le acompañaban regresaran a salvo, después de vencer al Minotauro y liberar a su patria del tributo de sangre que pagaba a Creta. Durante los días que tardaba el viaje del barco la ciudad tenía que mantenerse pura y toda ejecución quedaba suspendida, siendo ésta la causa de que Sócrates prolongara su vida por unos días más que gastó en los habituales diálogos con sus discípulos y amigos, entre los cuales se encontraba Cebes, a quien llamaban extranjero de Tebas. Poco se sabe de la vida de este filósofo tebano, pero debía ser joven cuando Sócrates bebió la cicuta. Diógenes Laercio, fuente principal para su biografía, lo presenta como autor de tres diálogos: Simmias, Phrinico y La Tabla. Los primeros se perdieron y la Tabla podría ser solamente una atribución, de acuerdo con un sector de la crítica que se ha apoyado en la presencia de algunos elementos peripatéticos y estoicos para considerarlo de época más tardía. Eñ todo caso, su estructura narrativa lo relacionaría mejor con los últimos diálogos platónicos que con la heurística de los propiamente socráticos. Hasta se podría pensar que la referencia a una "verdadera Institución", que parece aludir a la iglesia presentada como paradigma de la conducta del hombre,

${ }^{3}$ En el momento de entregar este artículo ha llegado a mis manos, por gentileza de la Dta. Elisa García Batragán, un ejemplar del Boletín del Museo e Instituto Camón Aznar, editado por Caja de ahorros de Zaragoza, Aragón y Rioja, núm. XIV-1983. Esta interesante publicación contiene un estudio de Santiago Sebastián López sobre el Theatro Mora de la Vida Humana de Otto Vaenius, del cual hace una erudita lectura e interpretación de los emblemas (que reproduce completos) Contiene también un estudio igualmente erudito de Pilar Pedtaza tituado La Tabla de Cebes. un jueguete filosófico. En éste, se reproducen el mismo grabado de la edición de Verdussen, una xilografía de Holbein de 1523, y una versión interesante por ser neoclásica y académica de L Enguídanos, ejecutada en Madrid en 1793 
remitiría a algún cristiano neoplatónico que compuso el diálogo y lo adjudicó o Cebes, que a fin de cuentas es el principal interlocutor de Sócrates en la exposición de la doctrina del alma. En una sociedad y en una época cuya filosofía fue el neoplatonismo, sería éste un buen ejemplo de los intentos por reconciliar la Teología con el pensamiento clásico.

El diálogo se plantea entre Cebes y un venerable viejo a quien llaman Gerondio, empleado este nombre como sinónimo de la sabiduría que trae aparejada la vejez. Cebes, que paseaba por el templo de Saturno, se encuentra ante una tabla (Pinax) o pintura que contiene "muy nuevas y nunca vistas siciones que no podía entender". Aquí aparece Gerondio que previa advertencia le va haciendo la explicación de la pintura. Representa ésta un monte, circunvalado por una triple muralla en cuya cima se levanta un templete (en nuestro grabado de aspecto bramantesco) al que se asciende por un camino que sube desde la base, esquivando obstáculos y que simboliza el camino del hombre. Este, representado en lo bajo del grabado por una muchedumbre - todavía en estado de ingenuidad- que se dispone a trasponer la primera puerta, recibe indicaciones de un genio que en su plena ascepción clásica le pone ante el buen y el mal camino.

$\mathrm{Si}$ asciende hasta la cima será bienaventurado; de otra manera pasará la vida en la ignorancia y la miseria. Pronto se enfrenta a las primeras acechanzas, como la elegante mujer (armada por el autor del grabado con los atributos de la vanidad) que le invita a beber engaño y perversión, las jóvenes y alegres mujeres que son los deleites y los apetitos y la fortuna que, loca e inconstante valsea sobre su esfera derramando lo que los hombres más estiman como verdaderos bienes: riquezas, honra, nobleza, señorios y sucesión. La disolución, la destemplanza y la lisonja son otras tantas rameras que flechan a los que reciben aquellos bienes de la Fortuna, conduciéndoles hasta una ergástula a que se humillen ante el castigo (figura armada con un látigo), el dolor (figura inclinada sobre las rodi1las) y el dolor (que se arranca los cabellos). Pero puede aun encontrarse con el arrepentimiento que le vuelve al camino que sube cuesta arriba. Otra mujer, en la puerta de la segunda muralla, procura atraerlo. Se ve muy bien compuesta pero denota poca cordura y menos honestidad; es la falsa Institución que algunos engañados toman como la verdadera, sumergiéndose en otra clase de deleites, aunque de orden superior. $Y$ entre estos engañados que avanzan cojeando - creyendo que bien caminan- pone Cebes a los oradores, poetas, dialécticos, músicos y filósofos. ${ }^{4}$ Los que

${ }^{4}$ Esto no es extraño, el mismo Sócrates, tratando de descifrar una respuesta del oráculo de Delfos, discute con hombres de estado, poetas y artistas, y en todos encuentra el mismo vicio: creen saber muchas cosas que en realidad ignoran. $\mathrm{Y}$ esto, a fin de 
pueden retomar la guía hacia la verdadera Institución subirán hasta la tercera muralla y la tercera puerta, angosta como el camino que la traspone y que va a concluir al pie de un collado muy alto y "agro", con grandes despeñaderos a los lados. Arriba hay dos mujeres hermosas que son la Continencia y la Constancia. - ¿Cómo subir a la peña? - pregunta el azorado Cebes, a lo que Gerondio responde que serán las dos mujeres las que tendiendo sus brazos halen al caminante. Le harán descansar dotándole de fuerza y osadía para que recorra lo que falta hasta la verdadera Institución. Una hermosa arboleda, cercada como el paraíso, señala la morada de la Bienaventuranza y las virtudes. Guarda la puerta otra mujer de mediana edad, rostro mesurado y atavío llano; es la verdadera Insti. tución cuyo atributo es la firmeza, indicada por la piedra cuadrada sobre la cual se para (opuesta a la bola mudable en que se sostiene la Fortuna) que obsequia al recién llegado con la poción que purga todo resabio de destemplanza, apetitos y avaricia. Otras jôvenes de buen parecer y bien criadas, que son las virtudes (Justicia, Fortaleza, Bondad, Templanza, Modestia, Liberalidad, Continencia y Clemencia) le conducen finalmente hasta la Bienaventuranza, hermosa mujer que mora en el templete, tipificado por los tratadistas como emblema de la Sabiduría, para que le corone igual que se corona al que sale vencedor en las justas. He vencido - -sentencia Gerondio- a los vicios y los monstruos que le devoraban. Ya podrá descender, seguro y bienaventurado, invulnerable al engaño, contemplando compasivo a los infelices que van extraviados, errado el camino y roídos por los vicios. Es en el grabado la figura del sabio que en su primer placer desciende sosegadamente, con la guirnalda del vencedor sobre sus sienes. Hasta aquí el argumento de La Tabla. ${ }^{5}$

La idea de representar como empinado monte la vida del hombre, considerada como vía de perfeccionamiento moral, arraiga sin duda en tradiciones medievales. Ya en el Fedón se halla sugerida en cuanto que se

cuentas, es lo que el oráculo quería decir: Sócrates era el más sabio porque él sí conocía su ignorancia sobre las mismas cosas que los otros, ignotándolas, decían conocer,

${ }^{5}$ Es interesante la relación que hizo Ambrosio de Morales entre el diálogo de la Tabla y una pintura que Felipe II había adquirido para el Escotial: El Carro de Heno, de Jerónimo Bosch, haciendo de ésta un comentario que se ha convertido eñ la pauta para toda exégesis sobre el simbolismo del Bosco. Se trata del famoso tríptico en cuyos postigos pintó el artista la caída de los ángeles rebeldes, la expulsión del paraíso y el infierno, dejando la tabla central para la representación de un carro de heno, como alegoría de la vanidad. Carro de heno afirma Morales, significa "carro de nonada"; el heno es riqueza efímera (como los dones y otros elementos en el diálogo de Cebes), es planta que muere sin dar fruto. Vid. Cinottí, Mia La obra pictórica completa de El Bosco. Introducción de Dino Buzzati. Biografía y estudios críticos de Mía Cinotti, Edit, Noguer, S A. 1968. 
habla de un ascenso y un descenso del alma, pero sería el cristianismo el encargado de darle un sentido trascendental y alegórico, partiendo de símbolos tan obvios como el Calvario o el Monte Carmelo. Como camino que conduce hasta la adquisición de la ciencia o el conocimiento fue $-\mathrm{y}$ creo que con frecuencia - representado en miniaturas. Mario Salmi ${ }^{6}$ reproduce una del italiano Attavante (1452-1517) en la que el monte se corona con una fuente - la fuente de la vida- y el árbol imagen de Cristo de cuyas ramas chorrea el agua. En las abruptas laderas se incrustan cabezas de demonios que vigilan el pesado camino. Nabucodonosor, émulo de la soberbia y la bestialidad, ni siquiera ha puesto el pie en el sendero, en tanto que Moisés, sentado en una piedra cuadrada como la que tiene la verdadera Institución en la Tabla de Cebes, descansa en lo alto, al pie de la fuente. Más cercanas a la Tabla son un par de miniaturas conservadas en la Biblioteca Nacional de Viena, miniadas en una Ética a Nicómaco que fue dedicada a Andrea Matteo Acquaviva. ${ }^{\top}$ En una se eleva el monte, con una figura en la cima que simboliza la virtud y sostiene en la mano una vara sobre la que hace equilibrio una manzana de oro, símbolo de la virtud aristotélica del justo medio. Una multitud trepa por las escarpaduras, ansiosa de alcanzar la cima, pero la mayoría se despeña porque no ha seguido el camino verdadero. En la segunda miniatura, la misma mujer que simboliza la razón recibe en la cumbre a cuatro hermosas jóvenes que también andan en la Tabla de Cebes: Prudencia, Fortaleza, Templanza y Justicia.

En el grabado de la Tabla hay un detalle gráfico que puede estar relacionado o cuando menos coincidir con la doctrina de la vía pasiva de los místicos. Pasada la tercera muralla, el sendero termina al pie de un collado por el que ya no se puede trepar. Solamente la Continencia y la Constancia que están arriba pueden ayudarlo tendiendo los brazos y halándolo a la peña; de otra manera no podría llegar a la Bienaventuranza. Se parece a la mística en que el alma, por propios actos (vía activa) en vías de perfeccionamiento alcanza un estado del que ya no le es posible pasar, pues solamente por un acto de gracia, dejando que Dios actúe en ella (vía pasiva) le será dable adquirir la suprema sabiduría (ciencia infusa).

Además de los fines morales a los que sirvió la figura del monte, en el siglo XVI llegó a sintetizar toda una doctrina, y no ligera, que fue la mística teología, expuesta primeramente en la Subida al Monte Sión de Ber. nardino de Laredo y, ya en grado sublime, en Subida al Monte Carmelo

\footnotetext{
${ }^{6}$ Salmi, Mario La Miniatura Italiana. Barcelona, Ed. Labor, S A, 1962, lámina 48.

${ }^{7}$ Alexander, J.J. Italian Renaissance illuminations. New York, George Braziller, 1977, láminas 35 y 36
} 
de San Juan de la Cruz. En nuestros días, y podríamos decir que a partir de la ilustración, el arte se ha desbordado para otros cauces que no son ya el solo camino religioso; y con el arte también, en necesaria concomitancia, los tradicionales sistemas iconográficos. Y, sin embargo, los símbolos de más entidad han subsistido, adecuando su forma hacia nuevas ideas y conceptos; como si el pensar y leer a través de los símbolos estuviera arraigado en la naturaleza misma del hombre. Uno de tales símbolos es la montaña, o el monte, capaz de sugerir altísimas abstracciones, como es la trascendentalidad, en pinturas como La Cruz de la Montaña de Caspar David Friedrich. Otras veces, el símbolo disuelve su formalidad y se diluye en la amplitud de la estructura literaria, por ejemplo en La Montaña Mágica de Thomas Mann. Hans Castorp, el visitante que procede del país Ilano, se incorpora paulatinamente al escogido grupo del Berghof que como una humanidad aparte va encontrando en la tara de la Tuberculosis el camino que conduce hasta la más completa comprensión de nuestra realidad viviente.

El tema de Cebes fue un rico venero para la producción de libros sobre moral, que aprovechando el sentido de teatralidad de los siglos barrocos se publicaron concibiendo la vida como un gran teatro en que los hombres son actores que desde la escena conminan al lector a discernir entre la buena y la mala conducta. Y como el texto, también el grabado hubo de responder a la necesidad de mostrar al hombre enfrentado a su des. tino. En la Biblioteca Nacional, en el fondo citado, hemos encontrado hasta ahora otras dos versiones del asunto moral tratado en la Tabla, sin dudar desde luego que al avanzar nuestra revisión irán apareciendo otras.

La primera versión corresponde a un libro francés publicado en el siglo XVII, el Theatrum Vitae Humanae escrito por Laurentio Beyerlinck e impreso en Lyon en 1678 por loannes Ant. Huguetan.

Lorenzo Beyerlinck (1578-1627) fue teólogo, canónigo y profesor de Filosofía en Amberes, su ciudad natal. La primera edición de su Magnum Theatrum Vitae Humanae apareció en Colonia en 1631.

La portada que reproducimos, de la edición lyonesa, está firmada por Gerard Audran, dibujante y grabador francés, nacido en Lyon en 1640 y muerto en París en 1703. Miembro de una familia de grabadores, trabajó con artistas como Charles Le Brun, en París, y Carlo Maratta y Ciro Ferri, en Roma, y según los datos que proporciona el diccionario de E. Benezit editó también algunas obras, entre ellas una importantísima que sería Les proportions du corps humaine (1693), según los cánones de la estética clásica.

La ilustración de Audran se inspira sin duda en el diálogo de Cebes, 
pero prescinde de la figura del monte y simplifica el tránsito escenográfico sintetizando las alegorías y resolviendo la plana en solamente dos secciones. La parte inferior es muy parecida a la que pocos años después publicarían los Verdussen: el mismo grupo que exhibiendo su estado de inocencia se apresta a cruzar bajo el arco que señala el principio de la vida (Introitus ad Vitam) se lee en la rosca del arco, escuchando previamente las advertencias del genio y bebiendo del cántaro que ofrece la elegante figura femenina, emblema del engaño y la seducción, en cuyo regazo descansa plácidamente el zorro, símbolo del engaño (no un gato como parece en la Tabla de Cebes). Traspuesta la muralla, el camino que tuerce a la izquierda conduce a la práctica de los oficios y las artes: quién pinta en caballete, la poesía con la frente ceñida con una corona de laurel, instrumentos musicales, esferas armilares, compases de trazo y escuadras. El camino que dobla hacia la derecha desemboca en una estancia en donde la fortuna derrama riqueza y cargos sobre eclesiásticos y soberanos. A otros, en contraste, les vuelve la espalda abandonándolos a la miseria y las enfermedades, en tanto que en el fondo se desatan escenas de pillaje y violencia, derivadas de la desigual distribución de la riqueza. En la parte superior del grabado, en correspondencia con los oficios, el artista representó a Hércules como símbolo del trabajo, rodeado de instrumentos de labor, y colgada al hombro la piel del león de Nemea. Detrás de Hércules, están siete hermosas mujeres que son las siete virtudes acompañadas de sus atributos (la Fe con el cáliz y la cruz, la Esperanza con un ancla, la Caridad abrazando dos niños, la Justicia que sostiene una balanza, la Prudencia con un espejo y una serpiente, la Fortaleza que sostiene una columna y la Templanza que escancia una jarra). Enfrente de Hércules y al otro lado del grabado se encuentra la voluptuosidad, elegante mujer que sostiene en las manos una copa y una rosa, y que es acompañada por una guitarrilla, un pequeño cupido, un tablero de juego, dinero y botes de perfumes y ungüentos. Detrás de esta dama y afrontadas a las virtudes, las siete figuras que representan los vicios (la Soberbia con un pavorreal, la Avaricia que aprieta una bolsa de dinero, la Ira que empuña una daga, la Lujuria con un macho cabrío, la Pereza, la Gula reclinada sobre un Cerdo y la Envidia con cabellera de serpientes y un corazón corroído. En el centro, en un globo que flota sobre nubes hay una reiteración de làs virtudes, en las 4 figuras ubicadas debajo de la cinta del zodíaco.

$\mathrm{La}$ otra versión que ahora publicamos se encuentra en la portada del libro Via Vitae Aeternae de Antoni Sucquet, teólogo jesuita, editado en Amberes por Martin Nuti, en el año de 1620. 
El texto y la portada fueron ilustrados con 2 grabados en metal por Boëtium Adams Bolswert, grabador holandés nacido en 1580 y muerto en 1633, discípulo de Cornelio Blomaert y hermano de Schelte Adams Bolswert, quien fuera miembro del grupo de extraordinarios grabadores de Pedro Pablo Rubens. La serie completa de grabados será publicada en un próximo número; por ahora solamente incluiremos la portada por tratarse de un dibujo simplificado de las vías y el monte que llevan al caminante hasta la bienaventuranza.

En esta portada, el ingreso a la vida está invertido, como si el lector estuviera observando desde dentro de la muralla. El río humano que va entrando se separa pronto en seguimiento de las dos direcciones señaladas, la que conduce por el camino de la virtud, como vía luminosa que termina en la luz de un rompimiento de gloria, y la que lleva por el vicio hasta el fuego del infierno, cuya puerta guarda una siniestra figura, según la peculiar manera de Bolswert, de representar los demonios como deformes grifos, inspirado probablemente en algún antiguo Bestiario. Nótese asimismo la psicología contenida en algunas figuras del primer plano, como el rapaz que hurta una bolsa o el religioso que camina con torva expresión.

El grabado de Bolswert se aparta de la representación tradicional del monte de Cebes, mientras que los de Audran y los Verdussen presentan varios puntos de semejanza. Es probable que ambos deriven de otro anterior. Viéndole en detalle, el flamenco tiene mejor dibujo; pero es posterior. Es posible - y así lo esperamos- que en el curso de nuestra búsqueda aparezca el que pudo servir como patrón para los que ahora publicamos.

Las fotografías para ilustrar este artículo fueron tomadas por la maestra Judith Puente León. 


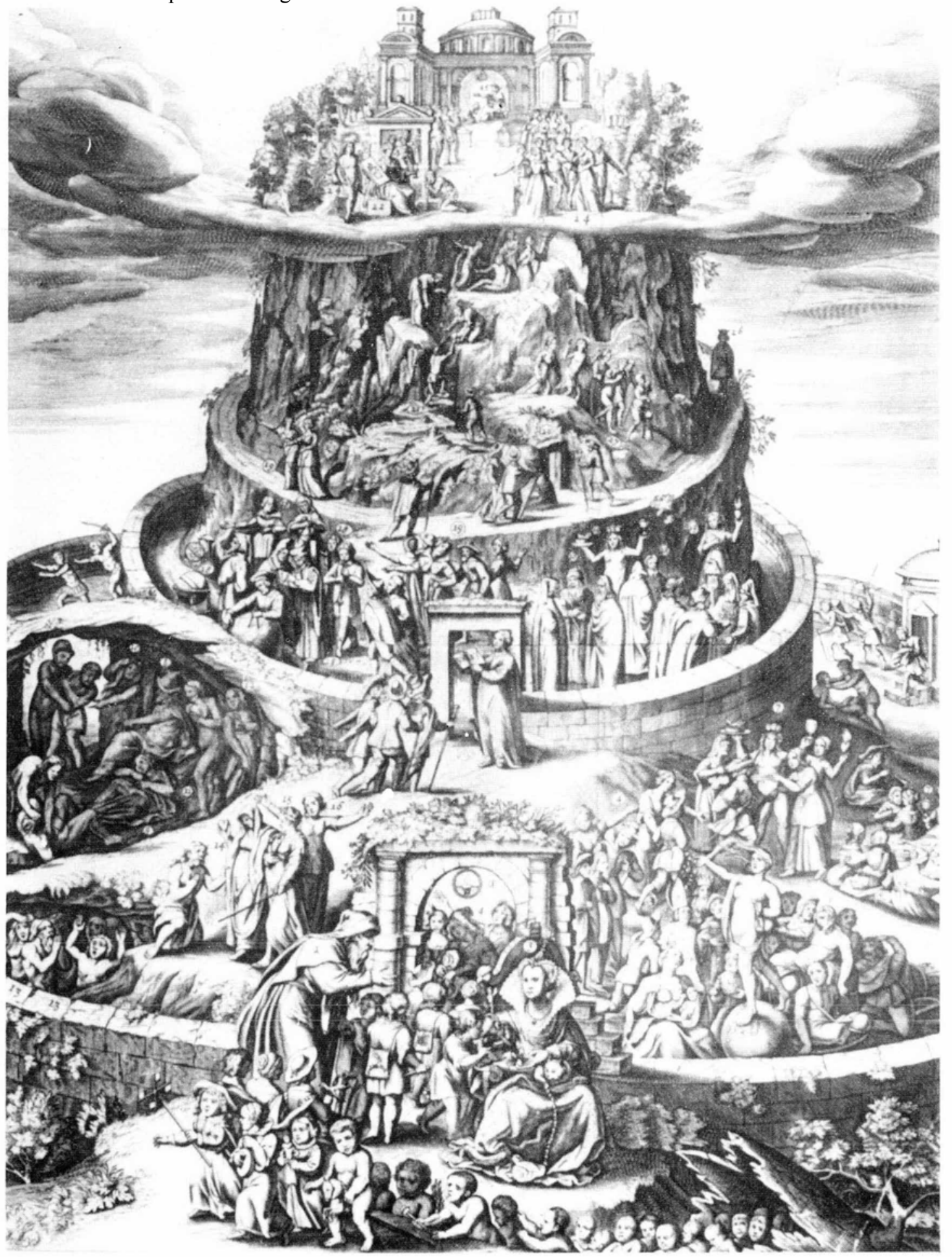

Figura 1. Tabla de Cebes. Grabado en metal, 1701. 
DOI: http://dx.doi.org/10.22201/iie.18703062e.1986.57.1336

\section{A L L E C T O R.}

T Emos añadido à efta Obra la Tablade Cebes, por fer una de las mejores cofas de la Antiguedad,y verdadera Puntura de la Vida Humana. Fue Cebes uno de los ma) res Pbilosophos de fu tiempo, que fue quatrocientos y jelenta años (poco mas, ò menos,) antes de la venida de lefu Cbrifto. La reputacion defte author, y de fu obra, fue tan univerfal, y tan eftumada defde veinte figlos aia; que ha fido traducido en differentes lenguas; y fe cuentan bafta quinze verfiones folamente Latinas de divergos Autores. Ambrojio de Morales Coronifta del Rey Pbilippo II. fiendo mogo, le traduxo de Griego en Ciaftellano: porque aunque fe avia impreffo en $P$ aris en Caftellano, eftava tan obfauro, y defectuofo, que no fe padia gozar de fubuena Doctrina, y nos Henrico y Corneho Verduffen Impreffores defta Obra, para dar todo el ajuftamiento y claridad poffible, bemos añadido la eftampa figurativa que era muy neceffarta, para la explicacion, fin reparar en el gran gafto, por fatisfacer à los curriofos.

\section{EXPLICACION DE LA ESTAMPA.}
r.
A puerta di la cerca de lavi- 9. La triftezs.
10. Lamifrits.
19. I amominencis, lalutaria,y
2. El Genio.
I. El fonrimienro in dolor.
20. Elodining de la veridaterado-
3. El Eng a rito.

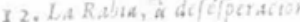
4. Las opiniones, los de feos, y los 13 . La caffa de la defarbis.

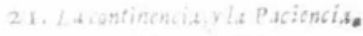 deleytes.
14. I a Penirencia.

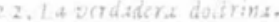
5. La fortuna
I S. La verdadera Opinion
6. Los recios.
16. Ia falfa opinion.
7. La incontinencia, la luxuria, la 17 . Laf falfa Aoctrina.
infaciabilidad, y la lifonja.
8. La pens.

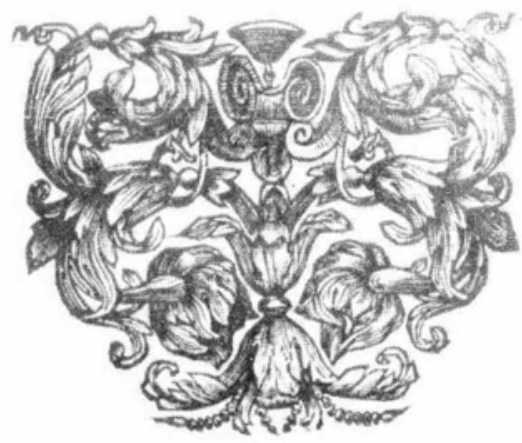

Figura 2. Tabla de Cebes. Explicación de la estampa. 
DOI: http://dx.doi.org/10.22201/iie.18703062e.1986.57.1336

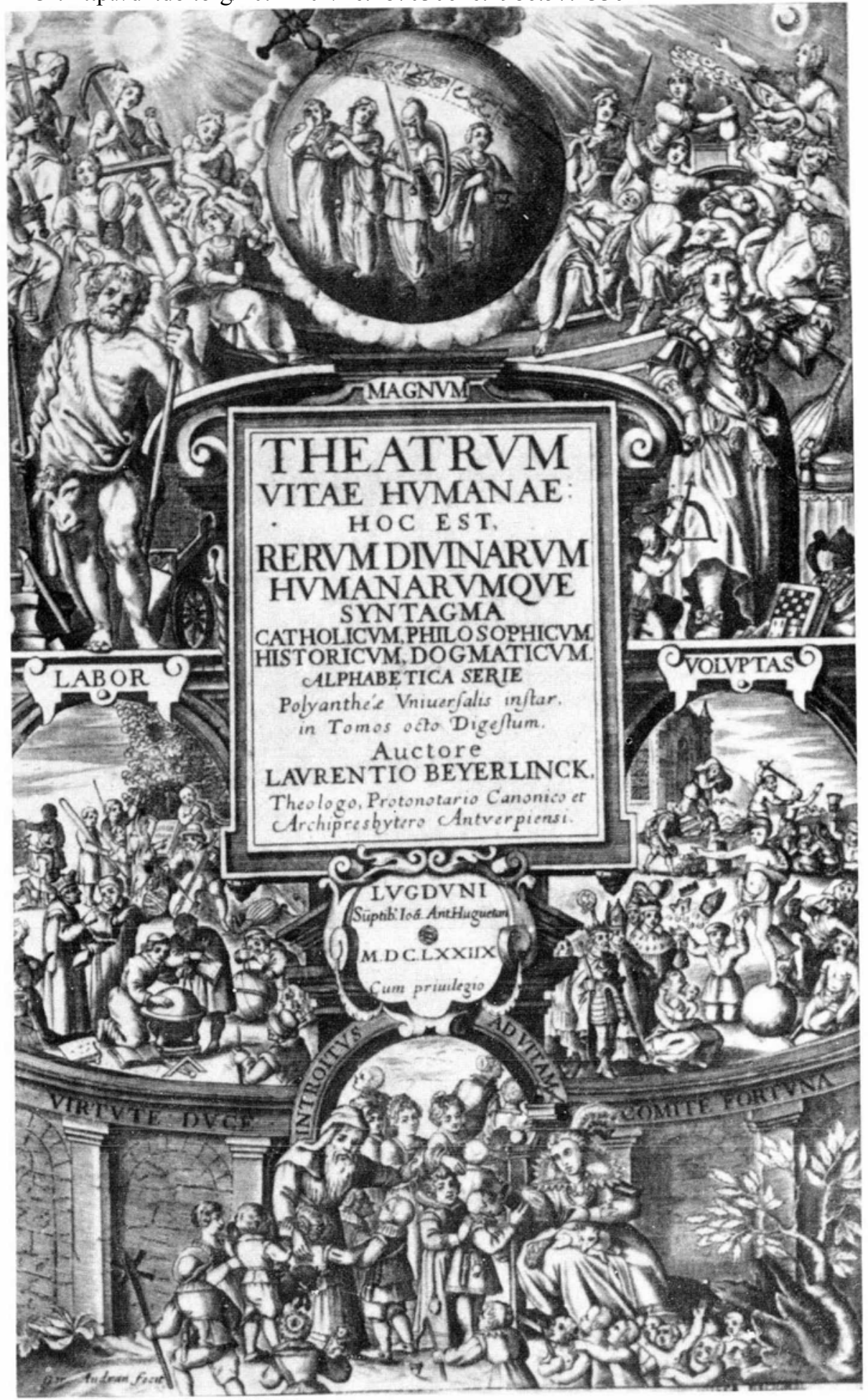

Figura 3. Portada para el Theatrum Vitae Humanae. 1678. Grabado en metal de Gerard Audran. 


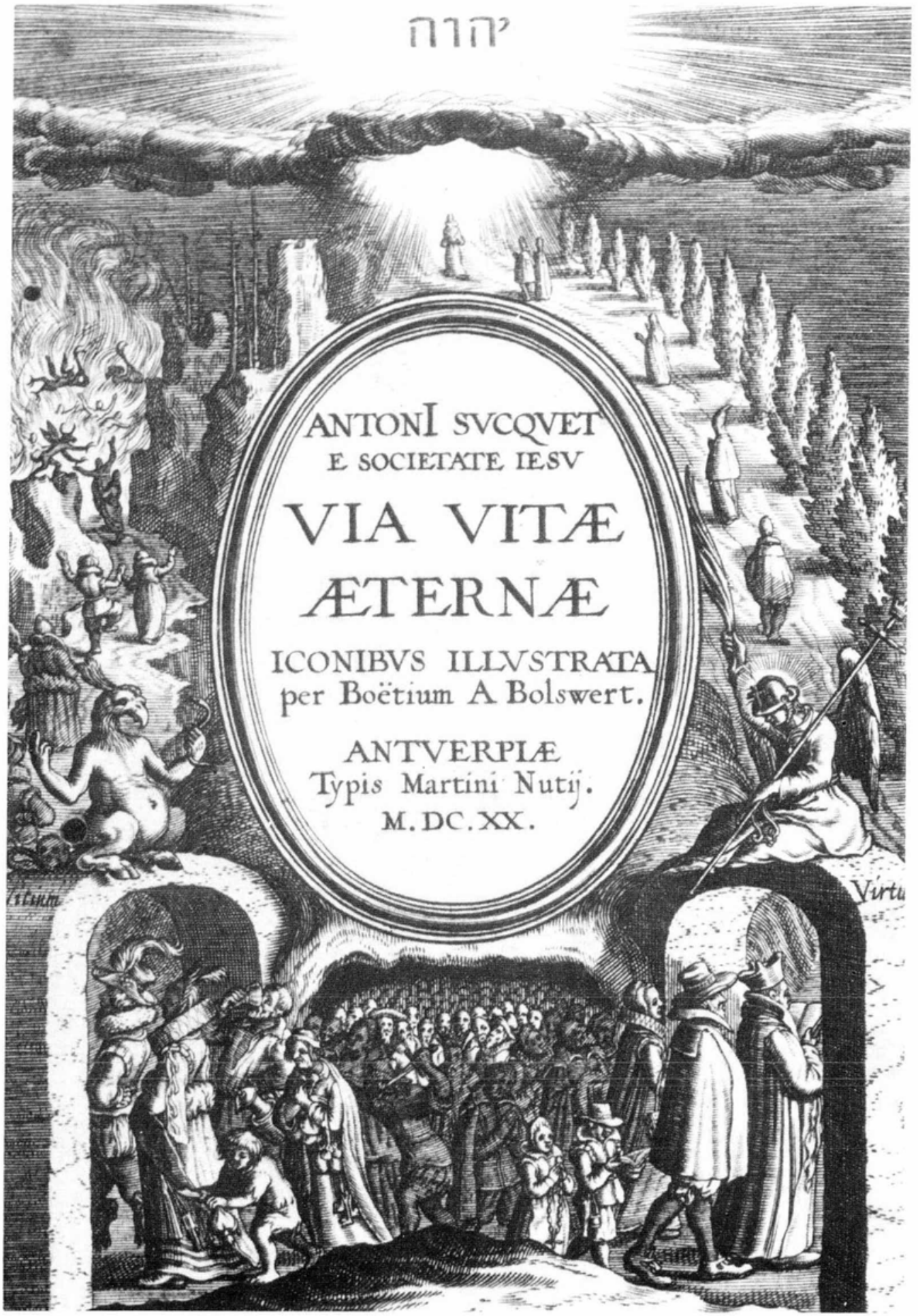

Figura 4. Portada para el libro Via Vitae Aeternae. 1620. Grabado en metal de Boëtium A. Bolswert. 